\title{
METODOLOGIJA DIZAJNIRANJA EDUKATIVNO TRENAŽNIH PROGRAMA
}

\author{
Vesna Nemec, \\ Predrag Nemec*, \\ Miloš Milošević
}

Univerzitet Singidunum, Beograd, Srbija

Odgovorno lice:

Predrag Nemec

e-pošta:

pnemec@singidunum.ac.rs
Rezime:

Cilj ovog rada je da prikaže metodologiju dizajniranja edukativno trenažnih programa. Shodno cilju rada, biće prikazani metodološki koraci, modeli i metode koje se koriste pri dizajniranju i kontroli edukativno trenažnih programa, izračunavanju i analizi njihovih efekta i promena u sportu. Semantičko logičko uobličenje svakog metodološkog koraka ima matematičku podlogu koja će se između ostalog koristiti u izradi softvera za programiranje edukacije i treninga u sportu. Posebno će biti data IT podrška metodologiji dizajniranja edukativno trenažnih programa.

Ključne reči:

Motorna kontrola, algoritam, metodologija dizajniranja, trenažni efekti, trenažne promene.

\section{TEORIJE NA KOJIM SE DIZAJNINJARAJU EDUKATIVNO TRENAŽNI PROGRAMI}

Pravljenje edukativno trenažnih programa zasnovano je na teoriji stacionarnog, aktuelnog i prelaznog stanja ili režima, teoriji razvoja, teoriji kapaciteta, strukturalnoj i funkcionalnoj teoriji sposobnosti, teoriji adaptacija i promena, teoriji efekata, teorijama stvaranja mišićne sile, teoriji učenja motornih algoritama i programa, teoriji motorne kontrole, integralnoj teoriji kretanja i stvaranja mišićne sile [1-11]. Svaka od teorija daje svoj puni doprinos u dizajniranju trenažnih programa.

\section{SEMANTIČKO LOGIČKO DEFINISANJE ALGORITMA}

\section{Prvi korak:}

Definicija populacije: uzrast u godinama, pol, podaci o senzitivnim zonama, zdravstvenom statusu, morfološkom statusu, o psihološkom statusu, podaci o fizičkom statusu, kapacitetima i nivou tehničko taktičkog znanja cele učeničke ili takmičarske populacije i pojedinaca u okviru nje [11]. 


\section{Drugi korak:}

Definisanje veličina kojima se procenjuju sposobnosti sportista, znanje, napredak, energetsko taktički zahtevi borbi - takmičenja, fizički status sportista, aerobni, anaerobni alaktatni i laktatni edukaciono-trenažni rad i trenažni rad u brzini i sili, saznajni efekti i promene, zatim mehanički, miogeni, neurogeni, energogeni, biohemijski i fiziološki efekti i promene u organizmu sportista [3-10].

\section{Treći korak:}

Definisanje objekata (obrazovni objekti, objekti koji definišu borbu - takmičenje, zatim aerobni, anaerobni i energetski status, status u brzini i sili itd.) koji će se menjati pod uticajem edukacije i treninga [1-10].

\section{Četvrti korak:}

Definisanje testova (program i postupak metrološkog merenja veličina) kojima se mere objekti, edukaciono trenažni rad, edukaciono trenažni efekti i promene [1-10].

\section{Peti korak:}

Definisanje operacija kojima se izračunavaju vrednosti u definisanim veličinama $[1,2,9]$.

\section{Šesti korak:}

Definisanje eksperimenta u kome će se izvršiti dijagnostika fizičko, obrazovnog statusa i trenažnog statusa za pojedinca, grupe, timove i populaciju određenog uzrasta [1-10].

\section{Sedmi korak:}

Izračunavanje početnog stanja i kapaciteta [1-10].

\section{Osmi korak:}

Izračunavanje i vrednovanje dinamike prirasta $\mathrm{u}$ praćenim promenljivim za pojedinca, grupe i populaciju u skladu sa mogućnostima sportista i zahtevima takmičenja $[1,2,7]$.

\section{Deveti korak:}

Izračunavanje idealnog finalnog stanja za pojedinca, grupe (taksone), timove i populaciju u praćenim promenljivim $[1,2,7]$.

\section{Deseti korak:}

Utvrđivanje razlika u početnim, tranzitivnim i finalnim stanjima među pojedincima i grupama u timu ili školi $[1,2,7]$.

\section{Jedanaesti korak:}

Definisanje materijalne osnove (uslova) u kojima se realizuju treninzi ili edukacija: broj igrališta, sala, otvorenih i zatvorenih terena, teretana, opreme, broj trenera, količina novca na raspolaganju, kalendar takmičenja [11].

\section{Dvanaesti korak:}

Izračunavanje vremenske edukaciono trenažne strukture: vreme trajanja pojedinih treninga izraženo $\mathrm{u}$ minutima, broj treninga u toku dana, broj treninga u toku nedelje, broj treninga u toku meseca ili godine, vreme trajanja treninga u toku jednog dana, nedelje, meseca, godine, izraženo u minutima, smenjivost režima dnevnog, nedeljnog i mesečnog trenažnog rada, izračunavanje vremenskog odnosa fizičke i tehničko taktičke pripreme po uzrastima i treninzima na godišnjem, mesečnom, nedeljnom i dnevnom planu, definisati periode u kojima nema takmičenja u kojima ima jedno, dva ili više takmičenja nedeljno, kao i ukupan godišnji broj takmičenja po uzrastima [1-10].

\section{Trinaesti korak:}

Definisanje skupa klasičnih i specifičnih edukaciono trenažnih sredstava koja će se koristiti za sva godišta tokom višegodišnjeg edukaciono trenažnog rada [1-10].

\section{Četrnaesti korak:}

Definisanje skupa edukaciono trenažnih metoda koje će se koristiti za sva godišta u višegodišnjem edukaciono trenažnom periodu [1-10].

\section{Petnaesti korak:}

Definisanje intencionalnog uticaja edukacije i treninga: oblast (osnovna, usmerena i napredna ili situaciona obuka), način uticaja (uspostavljajući, razvojni, održavajući, obnavljajući), režim uticaja - rada (aerobni, anaerobni...), vrsta uticaja (sva znanja i sposobnosti koja treba da se razviju po uzrasnim kategorijama) [7]. 


\section{Šesnaesti korak:}

Ubaciti zahtev o edukativno trenažnom programu: redni broj jednog ili više treninga, datum ili datumi za koji treba da se prave programi, ime i prezime sportiste ili grupe (tima - tim 1 ili tim 2), uzrast sportista [7].

\section{Sedamnaesti korak:}

Definisati (programirati) ciljeve treninga tj. izračunati trenutne i kumulativne edukativno trenažne efekate za pojedinog sportistu, za jedan ili više treninga u oblasti znanja, aerobije, anaerobije, brzine i sile na osnovu dijagnostifikovanog početnog stanja, dinamike njegovog napredovanja, zahteva borbe i materijalnih uslova [1-11].

\section{Osamnaesti korak}

(početak pravljenja sadržaja pojedinačnih treninga):

Definisati ciljeve i zadatke za konkretni trening, za konkretnog pojedinca, godište, grupu ili tim ${ }^{1}$ [1-11].

\section{Devetnaesti korak:}

Definisati vremensku strukturu konkretnog treninga koja odgovara materijalnim uslovima, uzrastu, nivou znanja, trenutnom statusu i dinamici napredovanja pojedinaca, tima ili grupe, koja će omogućiti postizanje definisanih ciljeva [1-11].

\section{Dvadeseti korak:}

Izračunati moguće finalno stanje u odnosu na: stvarno vreme trajanja edukativnog ili trenažnog procesa, materijalne uslove (oprema, sale, tereni, novac, kalendar takmičenja itd.), definisane ciljeve, inicijalno stanje uzrasta za koji se projektuju finalna stanja i zakonitosti po kojima se menjaju pojedine veličine odnosno komponente stanja sportiste $\mathrm{u}$ odnosu na senzitivne zone [1, $2,7]$.

\section{Dvadeset prvi korak:}

Izvršiti širi izbor klasičnih i specifičnih trenažnih sredstva koja odgovaraju uzrastu, nivou znanja i sposobnostima pojedinaca ili grupe, vremenskoj strukturi, periodu treniranja (period bez takmičenja, sa jednim ili dva takmičenja nedeljno) i ciljevima konkretnog treninga [3-10].

1 Isti metodološki postupak programiranja edukacije i treninga može da se primeni u svim sportovima uz male korekcije, zbog osobenosti određenog sporta, u pojedinim metodskim koracima.

\section{Dvadeset drugi korak:}

Izvršiti širi izbor trenažnih metoda po intenzitetu uticaja na znanja i sposobnosti pojedinaca ili grupe, i onih koje uz korišćenje izabranih sredstava omogućavaju postizanje postavljenih trenažnih ciljeva za konkretni trening $\mathrm{u}$ datom periodu treniranja (period bez takmičenja, sa jednim ili dva takmičenja nedeljno). Svaka metoda treba da je opisana efektima, brojem vežbi ili kombinacija vežbi, brojem ponavljanja vežbi ili kombinacija, trajanjem jednog ponavljanja, brojem i trajanjem pauza, trajanjem vežbanja ili brojem serija, brzinom izvođenja vežbe ili kombinacije, odnosno režimom rada [3-10].

\section{Dvadeset treći korak:}

Izračunati intencionalni uticaj (efekte i promene - napredak) izabranih trenažnih sredstava i metoda u planiranom vremenu na pojedincu ili grupi sportista. Zatim izvršiti vrednovanje njihovog uticaja i odabrati za konkretan trening samo one koje odgovaraju postavljenim ciljevima, programiranim promenama, dinamici razvoja znanja i sposobnosti pojedinaca u trenažno definisanom vremenu $[1,2]$.

\section{Dvadeset četvrti korak:}

Izračunati kapacitetne veličine rada koju sportista može da realizuje i izračunati i vrednovati individualne količine trenažnog rada koje će se realizovati u pojedinim treninzima (količina informacija, produkcija sile, produkcija energije, brzina vršenja rada, trajanje rada, prostorni parametri rada, veličina i učestalost vršenja rada, broj i trajanje pauza, itd.) koje će proizvesti programirane trenutne ili kumulativne efekte i promene (napredak u znanju, brzini, količinu stvorene sile, energije, mlečne kiseline, kiseoničkog duga, energenata, potrošnog kiseonika, glikogena, kreatinfosfata, povećanje brzine stvaranja sile, energije, napada, odbrana, kretanja, oporavka, razgradnje i resinteze energenata itd.) za jedan ili više treninga $[1,2,7,9]$.

\section{Dvadeset peti korak:}

Generisati, vrednovati i dati ispis najefikasnijih edukativno trenažnih programa za osnovnu i naprednu edukaciju u sportu i posebno edukaciju vođenja borbe ili takmičenja, za aerobni, anaerobni alaktatni i laktatni trenažni rad i trenažni rad u brzini i sili, kao i ispis trenutnih i kumulativnih obrazovnih, mehaničkih, miogenih, neurogenih, energogenih, biohemijskih i fizioloških efekata i promena, odnosno napretka, koje će izazvati 
programirani rad u jednom ili više treninga, za pojedini uzrast, tim, grupu ili pojedinca u toku jedne nedelje, meseca ili godine $[1,2,7]$.

\section{Dvadeset šesti korak \\ (početak evaluacije):}

Evaluacija kvaliteta edukaciono trenažnih programa $[1,2,7,9]$.

\section{Dvadeset sedmi korak:}

Evaluacija edukaciono trenažnih efekata i promena [1-10].

\section{Dvadeset osmi korak:}

Vraćanje na sedamnaesti korak.

\section{IT PODRŠKA METODOLOGIJI DIZANIRANJA EDUKATIVNO TRENAŽNIH PROGRAMA}

Pošto predložena metodologija zahteva složene operacije sa velikim brojem varijabli, kao i primenu relativno složenih matematičkih i statističkih postupaka, bilo joj je neophodno obezbediti informaciono tehnološku podršku praveći hardversko softverski sistem sa automatskom obradom i prikupljanjem podataka [7]. Osnovni cilj sistema bio bi osiguranje neophodnih podataka i informacija za planiranje, programiranje i kontrolu trenažnog procesa, praćenje i predviđanje stanja sportista u prostoru sposobnosti i unapređivanje njihove tehnologije rada.

\section{Posebni ciljevi IT sistema bi bili $[1,2,7]$ :}

- da na osnovu dovoljnog broja selektovanih, sređenih i za stručnjake razumljivih i primenljivih informacija, omogući utvrđivanje i praćenje stepena specijalnih sposobnosti,

- da na osnovu automatski prikupljenih podataka, zatim podataka prikupljenih merenjima ili testiranjima, pruži adekvatne informacije za programiranje, kontrolu i prognoziranje efekata sportskog napredovanja.

- da se na osnovu sređenih i upotrebljivih informacija o stanju pojedinih sportista izvrši profilisanje istih.

- da pravi razne vrste edukativnih i trenažnih programa i da kontroliše efekte i promene koje izazivaju,
- da stručnim telima i trenerima pruži informacije na osnovu kojih se može strateški planirati i valorizovati stručni rad u ovoj oblasti,

- da na osnovu prikupljenih informacija obezbedi racionalnu i egzaktnu selekciju potencijalnog sportskog kadra.

Za zadovoljavanje ovih zahteva treba da se formiraju četiri podsistema, i to [7]:

- podsistem informacija o motoričkim sposobnostima,

- podsistem informacija o specifičnim sposobnostima,

- podsistem informacija o trenažnim i edukativnim programima,

- podsistem za kreiranja trenažnih programa.

Pored ovih podsistema treba da budu formirana još dva podsistema za prikupljanje podataka o morfološkom i psihološkom statusu [7]. U okviru svakog od ovih podsistema funkcionisala bi određena baza podataka a u okviru podsistema za kreiranje trenažnih programa biće korišćenje razne vrste matematičkih i statističkih alata, kojima se analizira uticaj pojedinih edukativno trenažnih programa na promene stanja sportista, na osnovu čega bi bilo lako upravljanje trenažnim efiktima i promenama. Kao posledica urađenih analiza podsistem bi omogućavao pravljenje takvih trenažnih programa koji bi totalno bili prilagođeni ostvarivanju postavljenih ciljeva i zadataka određene sportske grane. Funkcije sistema bi bile akvizicija, unos i analize podataka, programiranje i kontrola edukativno trenažnih programa. U podršku metodologiji dizajniranja trenažnih programa spadaju programi za akviziciju sile, EMG, timinga, sa fotoćelija, sa kontaktnih platformi, moduli za unos podataka, izračunavanje koeficijenata eksponencijalnih jednačina, za izračunavanje spline metode koeficijenata jednačina, za grafičko prikazivanje jednačina, raport client, raporti, analize i priprema raporta kao i periferna oprema kao što je sistem senzora za beskontaktna merenja, platforma za merenje sile, video sistem, sonde dinamometri, oprema za testiranje funkcionalnih sposobnosti, kardio sposobnosti, biohemijska testiranja i antropometrijska testiranja.

\section{METODE ZA KONSTRUKCIJU ALGORITMA I ANALIZU TRENAŽNIH EFEKATA | PROMENA}

U pojedinim koracima pravljenja edukativno trenažnih programa koristiće se model slaganja, razlika, ostatka, linearni stohastički model, komponentni, taksonomski, kanonički i regresioni model $[2,7]$. 
Određivanje trenutnih i kumulativnih trenažnih efekata (ciljevi) za pojedinog sportistu, za jedan ili više treninga, vršiće se u skladu sa dijagnostifikovanim inicijalnim ili tranzitivnim stanjem i energetskim zahtevima takmičenja primenom polinominalnih trendova $[1,2,7,9]$.

Izračunavanje kapacitetne veličine rada koju sportista može da realizuje i individualno programiranje količine trenažnog rada (količina stvorene sile, brzina vršenja rada, trajanje rada, prostorni parametri rada, veličina i učestalost vršenja rada, broj i trajanje pauza, itd.) koja će u primeni proizvesti programirane trenutne ili kumulativne efekte, za jedan ili više treninga, vršiće se korišćenjem metoda nelinearne višestruke regresije $[1,2,7.9]$.

Analiza i vrednovanje tehničko taktičkog, aerobnog, anaerobnog alaktatnog i laktatnog trenažnog rada i trenažnog rada u sili, njegovih trenutnih i kumulativnih mehaničkih, miogenih, neurogenih, energogenih, biohemijskih i fizioloških efekata kod timova, reprezentacija ili cele sportske grane radiće se primenom kanoničkih i regresionih metoda sa i bez parcijalizacije predhodnih tranzitivnih stanja $[1,2,7]$.

Analiza stvarne i teoretske strukture trenažnih efekata za grupe, timove i reprezentacije radiće se različitim faktorskim modelima i metodama. Upoređenje energetske slike jednog treninga i energetske slike jedne borbe ili bilo kog vrhunskog takmičenja, radiće se korišćenjem kosih faktorskih solucija. Efikasnost edukativno trenažnog procesa određivaće se stepenom slaganja (Mahalobisovim odstojanjem) edukativno trenažnih efekata jednog treninga i energetskih zahteva i zahteva $\mathrm{u}$ sili jedne borbe ili bilo kog međunarodnog takmičenja (diskriminativna analiza). Komparativne analize, vrednovanje različitih edukativno trenažnih programa i izbor najboljih, radiće se korišćenjem taksonomskih i faktorskih metoda. Određivanje metrijskih karakteristika praćenih veličina, klasifikacija sportista i pravljenje normativa za vrednovanje edukativno trenažnih efekata radiće se korišćenjem faktorske i robusne diskriminativne analize $[1,2,7]$.

Izračunavanje intencionalnog uticaja (oblast, način uticaja, oblik uticaja, vrsta uticaja, režim uticaja, intenzitet uticaja...) trenažnih sredstava i metoda u planiranom vremenu radiće se korišćenjem metoda kanoničke i nelinearne višestruke analize $[1,2,7]$.

Određivanje konačnog broja trenažnih sredstava i metoda radiće se kosim solucijama faktorske analize $[2,7]$

Analiza kvantitativnih edukativno trenažnih promena (tehničko taktičke, mehaničke, miogene, neurogene, energogene, biohemijske i fiziološke) kod timova, reprezentacija ili u celoj sportskoj grani radiće se primenom modela razlika, modela slaganja, modela reziduala, linearnog stohastičkog modela i kanoničkog modela [1, $2,7]$.

Analiza kvalitativnih edukaciono trenažnih promena radiće se primenom komponentnog modela, taksonomskog modela, kanoničkog modela i analizom promena regresionih parametara [2,7]. Nastale promene analiziraće se i spektralnom analizom promena stanja jednog objekta (tehničko taktičko znanje, aerobija, anaerobija, sila, itd.), spektralnom analizom krivulja promena jednog obeležja (veličine) registrovanog na više entiteta $u$ više vremenskih tačaka, analizom apsolutnih i relativnih individualnih promena i analizom polinomijalnih trendova promena za pojedinca, timove, reprezentacije ili celu sportsku granu $[1,2,7]$.

Izračunavanje funkcija trenažnih promena za pojedinca, tim ili reprezentaciju u vremenu, određivanje metrijskih karakteristika praćenih veličina i pravljenje normativa za procenu trenažnih promena (napredovanja) radiće se korišćenjem taksonomske i nelinearne regresione analize $[1,2,7]$.

\section{ZAKLUČAK}

Na osnovu izloženog može se zaključiti da je potvrđen cilj ovog rada. Shodno cilju rada prikazani su metodološki koraci, algoritam dizajniranja, modeli i metode koje se koriste pri dizajniranju edukativno trenažnih programa. Zatim, izračunavanju, analizi i kontroli edukativno trenažnih efekta i promena. Posebno je opisan hardversko softverski sistem kao podrška predloženoj metodologiji. Osnovni cilj sistema bio bi osiguranje neophodnih podataka i informacija za planiranje, programiranje i kontrolu edukativno trenažnog procesa, praćenje i predviđanje stanja sportista u prostoru znanja i sposobnosti i unapređivanju trenažne tehnologije. Pri tome bi se koristila najsavremenija oprema za testiranje i kontrolu realizacije edukativno trenažnih programa.

\section{LITERATURA}

[1] Bonacin, D. (2012). Quantitative methods. Travnik: Faculty of Education.

[2] Momirović, K., Prot, F., Dugić, D., et al. (1987). Metode, algoritmi i programi za analizu kvantitativnih i kvalitativnih promena. Zagreb: Institut za kineziologiju Fakulteta za fizičku kulturu sveučilišta u Zagrebu. 
[3] Milosevic, BM. \& Milosevic, MM. (2013). Model for assessing the physical status, as well as prediction and programming of training and sports performance of a soccer player. Journal of Physical Education and Sport, 13(4):479 - 488.

[4] Milosevic, BM., Nemec, MP., Zivotic, RD., Milosevic, MM., \& Rajovic, DR. (2014). Force distribution model of motor units of leg extensor muscles. Journal of Sports Science, 2(3):195-199.

[5] Milošević, BM., Milošević, MM., Nemec, MP., Životic, RD. \& Radjo, II. (2014). A new approach to development of human maximal muscular force. Journal of Exercise Physiologyonline, 17(5):70-80.

[6] Milošević, BM., Džoljić, E., Milošević, MM \& Yourkesh, M. \& Behm, GD. (2014). The Analysis of Muscle Force Development with Trained and Elite Athletes. Physiology, 24(1-81):5-12

[7] Milošević, BM. \& Milošević, MM. (2014). SPECIAL PHYSICAL EDUCATION: Textbook on the management of the construction of the physical integrity and capacity of police officers. Saarbrücken, Germany: LAP Lambert Academic Publishing.
[8] Nemec, P., Milošević, MM., Nemec, V., \& Milošević, BM. (2016). Production and development of muscle force in elite male volleyball players' spike. Sport Science, 9(2):32-40.

[9] Milosevic, B.M., Nemec, V., Jourkesh, M., Nemec, P., Milosevic, M.M., Behm, D. (2016). Detrrmination of capacity and rules of the variability of maximum force using nonlinear athematical models: A case study. Central European Journal of Sport Sciences and Medicine, 16(4): 91.101.

[10] Milošević, M. B., Nemec, V., Nemec, P., Milošević, M. M., (2017). Programming methodology and control of aerobic training by running, Acta Kinesiologica, 11( 1): $53-57$.

[11] Tomić, D., \& Nemec, P. (2012). Volleyball in theory and practice. Beograd: SIA. 